\title{
INSTRUMENTAL COMMENSURABILITY
}

\section{FREDERICK SCHAUER ${ }^{\dagger}$}

What is commensurability, and what is incommensurability? Although the topic of commensurability has been discussed extensively by philosophers, lawyers, and others for more than two decades, ${ }^{1}$ the typical discussion of commensurability is an inquiry in moral ontology. That is, commensurability is taken to be a property inhering in values, reasons, options, or norms, and much of the debate is about whether that property does or does not inhere in all values, reasons, options, or norms, or, more accurately, in all pairs or sets of values, reasons, options, or norms. Those who argue for commensurability maintain that all values, reasons, options, or norms ${ }^{2}$ are reducible to some common and thus comparable metric (perhaps dollars, ${ }^{3}$ per-

† Frank Stanton Professor of the First Amendment and Academic Dean, John F. Kennedy School of Government, Harvard University. This Article was prepared for the Symposium on Law and Incommensurability, University of Pennsylvania Law School, February 6-7, 1998.

'Among the more noteworthy contributions to the debate are ELIZABETH ANDERSON, VALUE IN ETHICS AND ECONOMICS (1993); INCOMMENSURABILITY, INCOMPARABILITY, AND PRACTICAL REASON (Ruth Chang ed., 1997) [hereinafter INCOMMENSURABILITY]; MARTHA C. NUSSBAUM, Plato on Commensurability and Desire, in LOVE'S KNOWLEDGE: ESSAYS ON PHILOSOPHY AND LITERATURE 106 (1990); JOSEPH RAZ, THE MORALITY OF FreEdoM (1986); HENRY S. RICHARDSON, PRACTICAL REASONING About Final EndS (1994); Michael Stocker, Plural and Conflicting Values (1990); James Griffin, Are There Incommensurable Values?, 7 PHIL. \& PUB. AfF. 39 (1977); Richard H. Pildes \& Elizabeth S. Anderson, Slinging Arrows at Democracy: Social Choice Theory, Value Pluralism, and Democratic Politics, 90 Colum. L. REV. 2121 (1990); Joseph Raz, Facing Up: A Reply, 62 S. CAL. L. REV. 1153, 1218-22 (1989); Joseph Raz \& James Griffin, Mixing Values, 65 ARISTOTELIAN SOC'Y 83 (Supp. 1991); Donald H. Regan, Authority and Value: Reflections on Raz's Morality of Freedom, 62 S. CAL. L. REV. 995, 1056-75 (1989); Cass R. Sunstein, Incommensurability and Valuation in Law, 92 MICH. L. REV. 779 (1994); Richard Warner, Impossible Comparisons and Rational Choice Theory, 68 S. CAL. L. REV. 1705 (1995).

${ }^{2}$ The phrase "values, reasons, options, or norms" is designed to signal my agnosticism in this Article with respect to the contested question of what it is that is commensurable or incommensurable. Throughout the balance of this Article, I will use shortened versions of this cumbersome phrase, but only for stylistic purposes and not to indicate a withdrawal from my agnosticism.

${ }^{3}$ It is important to emphasize at the outset that nothing about the claim that all values or reasons are commensurable entails the claim that the common metric is money. See Richard Craswell, Incommensurability, Welfare Economics, and the Law, 146 U. PA. L. REV. 1419, 1421-22 (1998) (discussing different metrics). The debates about 
haps some other medium of exchange, perhaps utils, or perhaps something else). According to this position, the value or reason having or producing more of the property measured in the common metric is better than the value or reason having or producing less of that property. Relatedly, those who subscribe to the somewhat different position known as comparability ${ }^{4}$ maintain that all values, reasons, options, or norms can be compared to each other, even if they cannot be reduced to a common metric. ${ }^{5}$ Naturally, those who argue for incommensurability or incomparability deny the phenomenon of commensurability or comparability, and thus maintain that the members of some pairs or sets of reasons, values, options, or norms are irreducibly different.

My emphasis on the word "is" in my opening question is intended to signal a species of inquiry different from the one that provides the focus of most of the existing commmensurability literature. I will argue here that commensurability and comparability ${ }^{6}$ are not (or are

commodification plainly are related to the debates about commensurability. See, e.g., Scott Altman, (Com)modifying Experience, 65 S. CAL. L. REV. 293, 295-96 (1991) (describing commodification as "actions that... alter the sensibilities of people directly involved in market transactions by causing them to regard each other as objects with prices rather than as persons," and explaining how technological developments produce commodifying effects); Elizabeth S. Anderson, Is Women's Labor a Commodity?, 19 PHIL. \& PUB. AFF. 71, 71 (1990) (discussing the potential commodification of children and women's reproductive capacities resulting from surrogacy); Margaret Jane Radin, Justice and the Market Domain, in MARKETS AND JUSTICE: NOMOS XXXI, at 165, 165-67 (John W. Chapman \& J. Roland Pennock eds., 1989) (suggesting that traditional liberal views on commodification are overinclusive in the transactions they consider); Margaret Jane Radin, Market-Inalienability, 100 HARV. L. REV. 1849, 1851 (1987) (discussing how market inalienabilities can fit within an economic framework without being considered anomalies). For instance, a belief in universal commodification would presuppose the validity of commensurability. More reasonably, one could believe that all values or reasons are reducible to a common metric of utility, pleasure, self-expression, virtue, or something else, but are not reducible to a common metric of a medium of exchange. Nevertheless, the contingent social fact that since the early 1980 s, claims of commensurability have been associated with a dollar-denominated cost-benefit analysis is relevant to my larger claims in this Article, as existing social understandings plainly influence the determination of what dispositions, attitudes, rules, and decisionmaking structures would be morally best to have or to create.

'See Ruth Chang, Introduction, in INCOMMENSURABILITY, supra note 1, at 1 (explaining the difference between incommensurability and incomparability, and developing an account of comparability).

${ }^{5}$ Thus, it should be clear that commensurability entails comparability, but comparability does not presuppose commensurability.

${ }^{6}$ In the interests of economy of language I rarely will say "incommensurability or incomparability," but largely will use one or the other. This is not to deny the difference between the two, see supra note 4 , but only to make clear that, for my purposes here, the distinction is of little consequence. Everything that I say in this Article about 
not only) properties of sets of values or reasons that do or do not obtain. Rather, commensurability and comparability often have, or can be constructed to have, the character of attitudes, dispositions, presumptions, or conceptual frameworks, and, as such, they are best thought of as being chosen rather than as simply existing and, furthermore, as being chosen for instrumental and not intrinsic reasons. Why this is so, and why we might want to choose one or the other of commensurability and incommensurability, or of comparability and incomparability, are the central questions I will address in this Article.

I own a white 1990 Subaru Legacy station wagon. Suppose I happen to mention this fact to a friend, who responds that she has the same car. "No you don't," I reply. "You could not possibly have the same car. I have seen my car almost every day for the last seven years. And if you do not believe me when I say that the car you have is not the same car that I have, I will show you the serial number of mine, and that will prove conclusively that my car is not the same car as your car."

If I were to reply in this way, perhaps my friend would assume that I was being odd, or that I was making a weak and unsuccessful attempt at humor. And she would assume one of these things because the word "same," which in some contexts denotes identity (the person who came to my door today was the same person who came to your door yesterday ${ }^{7}$ ), in many other contexts, including this one, denotes something else. The use of the word "same" often suggests not only that a number of relevant similarities exist even in the face of dissimilarities, but also that in the instant context these dissimilarities are immaterial. Although your car is not my car, and although we are talking about two cars and not one car, we commonly use words of identity-"same," "equal," "alike," "identical," "exact" -in a particu-

one could be said about the other, even if everything that could be said overall about one could not necessarily be said about the other.

${ }^{7}$ Perhaps not. See Derek Parfit, Reasons AND PERsons 199-201 (1991) (exploring the concept of personal identity by postulating a science-fiction hypothesis in which people are blueprinted, destroyed, and then reconstructed in another place).

${ }^{8}$ My former father-in-law, a mathematician, thought the following joke was enormously funny: A country carpenter comes to the city and takes a tour of a modern technological laboratory at a place like M.I.T. In one of the labs, a scientist shows off an impressive-looking apparatus, and says to the carpenter, "This is an atomic ruler, and it can measure length to within one one-hundred thousandth of an inch." "I 
lar kind of context-dependent way. Even though we recognize that there are, in a literal sense, differences of one kind or another, we suppress these differences or inexactitudes, because the points of convergence are far more important in some contexts than the points of divergence. My example shows that there are contexts in which you would say that your car is the same as my car even if the two were different cars, and even if you would not trade your car for mine. Numerous common expressions-"close enough for government work"; "six of one and half a dozen of the other"; "it's all the same to me"; "Tweedledum and Tweedledee"-all reflect the frequency with which, for various strategic or instrumental reasons, we commonly treat things that are in some respects different as if they were the same. ${ }^{9}$

We see the same phenomenon in the context of the ordinary discourse surrounding the concept of political, moral, and social equality. When the authors of the Declaration of Independence announced that "all men are created equal," they did not suppose that even the people of whom they spoke (a subset of all people, and a subset of all men) were in fact equal in all respects, or even in all relevant respects. Their claim of equality was not a descriptive one, but one that was in part aspirational, and in even larger part norma-

suppose that's good enough here in the laboratory," says the carpenter, "but in my business we have to be exact."

${ }^{9}$ As is often the case in these kinds of inquiries, J.L. Austin said it first, and best:

"The same" does not always mean the same. In fact it has no meaning in the way that an "ordinary" word like "red" or "horse" has a meaning: it is a (the typical) device for establishing and distinguishing the meanings of ordinary words. Like "real," it is part of our apparatus in words for fixing and adjusting the semantics of words.

J.L. AUSTIN, Truth, in PHILOSOPHICAL PAPERS 85, 88 n.2 U.O. Urmson \& G.J. Warnock eds., 1961). The phrase

"[i]s of a type with which" means "is sufficiently like those standard states of affairs with which." Thus, for a statement to be true one state of affairs must be like certain others, which is a natural relation, but also sufficiently like to merit the same "description," which is no longer a natural relation. To say "This is red" is not the same as to say "This is like those," nor even as to say "This is like those which were called red." That things are similar, or even "exactly" similar, I may literally see, but that they are the same I cannot literally see-in calling them the same colour a convention is involved additional to the conventional choice of the name to be given to the colour which they are said to be.

Id. at 90 n.2; see also J.L. AUSTIN, SENSE AND SENSIBILIA 41-42, 74-76 (G.J. Warnock ed., 1962) (describing "like" as an "adjuster-word"). Austin also argued that many words, such as "precise," "exact," and "accurate," are similarly context-, speaker-, and purposedependent. See id. at 126-29, 128 (stating that "what is precise (enough) for some purposes will be much too rough and crude for others"). 
tive. As with claims of identity, likeness, exactness, and sameness, claims of equality are not ordinarily claims of literal equality in all respects, or even in all potentially relevant respects, but rather they are claims that people should be treated the same in some number of respects because they are the same in some, but clearly not in all, respects. $^{10}$

The same phenomenon of attributing sameness on the basis of partial similarity could, and often does, work in reverse as well, such that we attribute difference even in the face of substantial similarity. Thus, we frequently exaggerate differences in some contexts that in other contexts would be inconsequential. The (perhaps apocryphal) ${ }^{11}$ claim that the Inuit have a very large number of different words for snow is a prominent example, but the same phenomenon occurs in ordinary talk. When we say "it's not the same," we often mean that in the face of numerous similarities, and in the face of superficial identity, there is a difference that is particularly relevant in some context. Just as assertions of sameness are typically contextdependent, instrumental assertions of relevant sameness in the face of some number of differences, so too are assertions of difference typically context-dependent, instrumental assertions of relevant difference in the face of some number of similarities between the compared particulars.

\section{II}

What emerges from this brief look at the ordinary language of sameness and difference is the suspicion that claims of equality (and inequality), sameness (and difference), and equivalence (or nonequivalence) are more purposive and instrumental and less descriptive than they may seem at first sight. Moreover, the purposes and

${ }^{10}$ In some respects, therefore, attributive claims of sameness, identity, and equality are like claims of analogy. See Larry Alexander, Bad Beginnings, 145 U. PA. L. REv. 57 (1996) (casting doubt on reasoning by analogy as a discrete form of reasoning); Scott Brewer, Exemplary Reasoning: Semantics, Pragmatics, and the Rational Force of Legal Argument by Analogy, 109 HARV. L. REv. 923, 978-83 (1996) (explaining the partially distinct nature of reasoning by analogy in terms of abductive reasoning); see also JOSEPH RAZ, Law and Value in Adjudication, in THE AUTHORITY OF LAW 180, 201-06 (1979) (explaining reasoning from precedent in terms of shared features of the precedent case and the novel case). With respect to precedent and analogy, however, the common understanding of the ideas recognizes the lack of complete similarity. When we talk of identity, sameness, likeness, or equality, however, the fact that the equivalencies are only partial is less apparent, although, as I argue here, no less real.

"See GeOFFrEy K PULLUM, THE GREAT ESKIMO VOCABULARY HOAX 159-71 (1991). 
goals behind the use of such words and phrases may involve normative and prescriptive claims as well as descriptive statements. And when claims that look descriptive on their face turn out to be prescriptive and normative, a cluster of related philosophical contributions becomes relevant.

The first member of this cluster of ideas is the concept of emotive meaning. The notion of emotive meaning, often associated with the work of Charles Stevenson, ${ }^{12}$ suggests that the purpose of a great deal of superficially descriptive language is to express the speaker's pro or con attitude about what it is she is literally only describing. For instance, in modern discourse, whether a speaker refers to certain employment and admissions policies as "affirmative action" or as "reverse discrimination" tells us a great deal about her views on such policies. Similarly, we can surmise a person's opinions on some issues of social policy based on whether she identifies an individual as a "homeless person" or as a "tramp."

Stevenson and his followers believe that this kind of "Boo!Hurrah!" connotation is a large part of ordinary talk, and, in particular, the ordinary talk that claims to be morally descriptive, as in "it is wrong to have sex outside of marriage." For Stevenson and many others, ${ }^{13}$ the best translation of "it is wrong (or right)" and other seemingly descriptive statements is "I like it" or "I do not like it."

Related to this account is the more recent literature on "thick descriptions, ${ }^{\not 14}$ as most carefully developed by Philippa Foot ${ }^{15}$ and

12 See Charles L. StEvenson, Ethics and LANGUAGe 33 (1944) ("The emotive meaning of a word is the power that the word acquires, on account of its history, in emotional situations, to evoke or directly express attitudes, as distinct from describing or designating them."); Charles L. STEVEnSON, FACTS AND VALUES 8 (1963) (explaining briefly why "ethical terms, such as 'good,' 'wrong,' 'ought,' and so on, are so habitually used to deal with disagreement in attitude"). Also useful is CARL WELLMAN, THE LANGUAGE OF ETHICS (1961).

${ }^{13}$ Jeremy Bentham, for one, was persistently annoyed with what he called "passionkindling appellatives" and "impostor terms." See H.L.A. HART, The Demystification of the Law, in ESSAYS ON BENTHAM 21, 27 (1982) (arguing that Bentham preferred the use of neutral terms so as not "to cloud the issues in controversy").

${ }^{14}$ I am not referring to this term as it is used, primarily by Clifford Geertz and his followers, in the context of anthropological investigations. See CLIFFORD GEERTZ, Thick Description: Toward an Interpretative Theory of Culture, in THE INTERPRETATION OF CULTURES 3, 6 (1973) (explaining that "thick description" defines the intellectual effort involved in ethnography).

${ }^{15}$ See PHILIPPA FOOT, Moral Arguments, in VIRTUES AND VICES AND OTHER EsSAYS IN MORAL PHILOSOPHY 96 (1978). Related discussions can be found in JUDITH JARVIS THOMSON, THE REALM OF RIGHTS 10-20 (1990), which gives examples to support Foot and Bernard Williams's argument that "much of our moral thinking is neither purely 
Bernard Williams. ${ }^{16}$ When we appear to describe some behavior as "rude," to use one of Foot's examples, ${ }^{17}$ we are not just describing it. Instead, we are either personally condemning the behavior or, at least, describing the fact of extant societal condemnation. Whether the condemnation comes from the speaker or from the community at large, the important point is that the condemnation is part of the meaning of words like "rude." To describe behavior as both rude and praiseworthy would be to engage in an act of linguistic selfcontradiction. Many other descriptions-for example, "adorable," "pushy," "imposing," "bum," "hero"-are in part descriptive because someone in agreement with the normative standards implicit in one of these words could still disagree with the word's application to a particular case. The words, however, are not only descriptive, because, in the process of describing, the describer is also making or subscribing to a normative or evaluative claim, or at the very least describing a normative or evaluative claim made by someone else or by society at large.

The idea of thick descriptions suggests, in turn, the concept of ascriptive language. In his earliest work, H.L.A. Hart suggested that all of legal language is ascriptive, in that legal language characteristically announces a legal conclusion rather than describes a hard fact about the world. ${ }^{18}$ To say that a transaction is a contract, or that a defendant is guilty, or that some form of behavior is a tort, Hart argued, is not to identify some raw and pretheoretical fact. Instead, it is to announce a legal outcome, and thus to ascribe to a set of facts a certain legal conclusion. ${ }^{19}$ As G.P. Baker paraphrases Hart's basic point: “[S]entences of the form 'He did it' are primarily used to ascribe responsibility for actions, not to describe a person's actions." ${ }^{20}$ Although Hart was

factual nor purely moral," and John McDowell, Are Moral Requirements Hypothetical Imperatives?, 52 ARISTOTELIAN SOC'Y 13, 24 (Supp. 1978), which rejects Foot's belief "that moral requirements exert a rational influence on the will only hypothetically."

${ }^{16}$ See Bernard Williams, Ethics and the Limits of Philosophy 129 (1985) (explaining that thick ethical concepts "express a union of fact and value").

${ }_{17}$ See FOOT, supra note 15, at 102-05, 103 (explaining that "the meaning of 'rude' is given by the attitude it expresses").

${ }^{18}$ See H.L.A. Hart, The Ascription of Responsibility and Rights, 49 Proc. ARISTOTELIAN SOC'y (n.s.) 171 (1949). Similar themes are explored in H.L.A. HART, Definition and Theory in Jurisprudence, in ESSAYS IN JURISPRUDENCE AND PHILOSOPHY 21, 23-26 (1983).

${ }^{19}$ See Hart, supra note 18.

${ }^{20}$ G.P. Baker, Defeasibility and Meaning, in LAW, MORALITY, AND SOCIETY: EsSAYS IN HoNOUR OF H.L.A. HART 26, 29 (P.M.S. Hacker \& J. Raz eds., 1977) [hereinafterLAw, MORALITY, AND SOCIETY]. 
properly criticized $^{21}$ for failing to recognize that even these ascriptive conclusions presuppose certain descriptive antecedents-for example, in finding a defendant guilty, the jury not only announces a legal conclusion, but also determines that certain raw facts actually occurred-the more moderate point that still emerges is that a great deal of legal language not only describes facts, but also ascribes conclusions that flow from the described raw facts. Although "he did it" purports to describe an "it" that the defendant actually did, it also ascribes responsibility based on what is an undeniably evaluative or normative framework.

There are, of course, important differences among these three ideas-emotive language, thick descriptions, and ascriptive language-but the similarities are what most interest me here. The lesson that emerges from all three is that one need not reject the factvalue distinction nor subscribe to the central tenets of continental philosophy in order to recognize that descriptive sentences containing seemingly descriptive words arrayed in a seemingly descriptive semantic structure often mask statements and conclusions that are in important ways normative, evaluative, and prescriptive. Moreover, language often operates to make descriptive statements serve underlying normative ends, and what appear to be descriptive statements often emerge as a consequence of creating, for instrumental reasons, a certain kind of evaluative framework.

III

As should be evident by this time, my claim is that conclusions of commensurability (or incommensurability) or comparability (or incomparability), or statements about commensurability and comparability, are or can be thick or ascriptive in just this fashion. These conclusions are more than descriptions of the terrain of value or the landscape of reasons. They are evaluations of that terrain, or even impositions on that terrain, and, as such, presuppose the standards,

${ }^{21}$ See P.T. Geach, Ascriptivism, in ETHICs 22, 22 (Judith J. Thomson \& Gerald Dworkin eds., 1968) (refuting the argument of "some Oxford philosophers [who] have resorted to denying that to call an act voluntary, intentional, and so forth, is any sort of [causal] statement, or indeed any statement at all"); George Pitcher, Hart on Action and Responsibility, 69 PHIL. REV. 226 (1960) (pointing out the descriptive components of ascriptive language). Hart acknowledged the form of these criticisms in his preface to H.L.A. HART, PUNISHMENT AND RESPONSIBILITY (1968). A good subsequent discussion describing Hart's rationales for his antireductionist stand in jurisprudence is found in Baker, supra note 20, at 28-35. 
goals, and purposes that such an evaluation or imposition might be thought to serve. Once we see that even claims of equality or identity may involve instrumental selections of relevant similarities in the face of irrelevant differences, we can see as well that a very similar claim of comparability or commensurability may involve selecting comparable parts from incomparable wholes, or focusing on commensurable properties from among otherwise incommensurable pairs. To say that $a$ and $b$ are commensurable may very well be to ignore certain incommensurable properties of $a$ and $b$, but that is not to make a false statement any more than it is false to say that your car is the same as my car. It is only to apply to conclusions about incommensurability the same linguistic and conceptual machinery that we apply to most other claims of sameness and identity. The question then is not whether it is "permissible" to do so, but only whether we, as a certain linguistic subcommunity, have in fact done so, or whether we would want to do so.

In pursuing this line, I do not want to argue that claims of commensurability or incommensurability are necessarily ascriptive. As most of the participants in the incommensurability debates plainly believe, and rightly so, there is a nonnormative fact of the matter, and these participants appear committed to discovering what that fact of the matter is. Although an assertion of commensurability could be a descriptive claim, I think that I have demonstrated that it could be an ascriptive one as well. And if this is so, then one option is not only to understand the existing language of the commensurability debates in thick or ascriptive terms, but also self-consciously to create or construct the discourse in this way, in order, instrumentally, to serve certain normative or prescriptive functions. To put it differently, ascriptive language and other forms of value-laden or purposive description are within a linguistic community's capabilities to create. An important normative question, therefore, is whether a community should create such a discourse or understanding, and this question could be considered important even while recognizing that the onto-

${ }^{22}$ The fact is a normative fact, but the identification of a normative fact is not necessarily a normative act. Without delving too far into metaethics or moral epistemology, it seems clear that any objectivist metaethics, like any other observerindependent inquiry, presupposes the ability to identify the object of morality independent of the identifier's moral views. 
logical questions about commensurability still might and still should be pursued. ${ }^{23}$

At this point, I want to bring into the discussion one more cluster of ideas from the shelves of the philosophical warehouse. This is the cluster that includes rule-utilitarianism, dispositional utilitarianism, and all other forms of "indirect consequentialism. ${ }^{24}$ The basic idea is that we might best maximize consequences over an array of decisions or events if we avoid attempting to maximize the consequences in each individual case, and instead put in place a decision procedure or rule or heuristic, or internalize or inculcate a disposition, ${ }^{25}$ which, if followed in every case, will produce better consequences in the aggregate than would be produced by attempting to maximize the consequences directly in each case.

The best and first presentation of the idea I want to deploy is John Stuart Mill's discussion of justice in chapter five of Utilitarian${ }_{i s m .}{ }^{26}$ In urging the widespread acceptance of a (nonutilitarian) norm of justice, Mill did not believe that a norm of justice was descriptively accurate, in the sense of actually mirroring what morality actually is. Unsurprisingly, the Mill who wrote Utilitarianism can be taken to have believed that utilitarianism provided the best account of morality, ${ }^{27}$ and that consequently the morally best world would be achieved, under ideal circumstances, if we simply maximized utility in every case. But Mill also recognized that a range of factors-

${ }^{23}$ In the discussion that follows, I expand on an argument for an instrumental approach to the commensurability debate that I first suggested in Frederick Schauer, Commensurability and Its Constitutional Consequences, 45 HASTINGS L.J. 785, 786 (1994).

${ }^{24}$ For an especially insightful overview of the philosophical terrain, see Larry Alexander, Pursuing the Good-Indirectly, 95 ETHICs 315, 330 (1985). For an earlier collection of contributions to the debates about act- and rule-utilitarianism, see CONTEMPORARY UTILITARIANISM (Michael D. Bayles ed., 1968). Also useful is Dan W. Brock, Recent Work in Utilitarianism, 10 AM. PHIL. Q. 241 (1973), which surveys utilitarian theory from 1961 through 1971.

${ }^{25}$ For a discussion of utilitarian dispositions, their uses, and their inculcation, see Robert Merrihew Adams, Motive Utilitarianism, 73 J. PHIL. 467 (1976), and Philip Pettit \& Geoffrey Brennan, Restrictive Consequentialism, 64 AUSTRALASIAN J. PHIL. 438 (1986).

${ }^{26}$ JOHN STUART MILL, Utilitarianism, in ESSENTLAL WORKS OF JOHN STUART MILL 183, 226-48 (Max Lerner ed., 1961).

${ }^{27} \mathrm{I}$ avoid as unnecessary for my argument the question whether the John Stuart Mill of Utilitarianism, or the John Stuart Mill of On Liberty, was "really" a utilitarian. See David Spitz, Preface to JOHN STUART MILl, ON LIBERTY at vii, vii-viii (David Spitz ed., 1975) (noting that several scholars found Mill's writing in On Liberty inconsistent with his other writings). The point here is only that a thoroughgoing, internally consistent, take-no-prisoners utilitarian, which Mill may or may not have been, could, consistent with that utilitarianism, urge the internalization and/or propagation of decidedly nonutilitarian dispositions. 
including what we might identify now as mistake, lack of understanding, lack of time, bias, conflict of interest, and weakness of the willmight produce less overall morality in a world of widespread case-bycase calculations of utility than would be produced if people followed the (presumed to be) theoretical suboptimal dictates of justice. ${ }^{28}$

What makes Mill's approach so relevant here is not as much its rule-based descendants ${ }^{29}$ as its articulation of what we now think of as dispositional utilitarianism. ${ }^{30}$ If people were to internalize or train themselves to certain dispositions, then those dispositions, once followed, might be the route to the best overall consequences. Importantly, this would be so even if the dispositions would be unnecessary or suboptimal in an ideal world. So if, for example, I suspect that my own soft-heartedness would produce a lower-than-ideal level of utility for the decisions I have to make, I might, for good utilitarian reasons, train myself to be especially hard-hearted or callous. Although this strategy might produce a suboptimal level of utility if appended to the dispositions of normal people, it likely would produce something closer to the optimal level of utility when appended to the abnormally soft-hearted, like myself.

\section{IV}

Now, consider all of this in the context of commensurability and incommensurability. The question is no longer only which of these alternatives is true, but also which of these alternatives, if widely accepted, or if accepted by a certain cadre of public decisionmakers, would produce the best consequences, or the morally best world. Thus, if we view commensurability and incommensurability not only as positions that might be true or false, sound or unsound, justified or unjustified, but also as dispositions, attitudes, or presumptions that people might possess, then the question is whether morality would be better served if decisionmakers had one or the other attitude, disposition, or presumption.

${ }^{28}$ Moreover, a large range of problems of coordination and co-operative behavior, of which the prisoner's dilemma is only one, may also argue against direct utilitarianism. See DONALD REGAN, UTILITARIANISM AND CO-OPERATION 63 (1980) (concluding that "an 'act-utilitarian prisoner's dilemma' cannot exist").

${ }^{29}$ I discuss some of these descendants in FrEDERICK SCHAUER, PLAYING BY THE RULES: A PHILOSOPHICAL EXAMINATION OF RULE-BASED DECISION-MAKING IN LAW AND IN LIFE 86-88 (1991). ism).

${ }^{30}$ See supra note 25 and accompanying text (discussing dispositional utilitarian- 
Part of this inquiry turns on a series of psychological speculations ${ }^{31}$ about how some cohort of people will make decisions if it believes that there are, or are not, conflicts between incommensurable values or reasons. Suppose, first, that a cohort of people believes that there are some incommensurable values or reasons. Given this belief, it is possible that such people, knowing that there are some incommensurables, will make decisions under an implicit or de facto decision procedure that takes there to be more incommensurables than there in fact are. Believing that there are some incommensurables, or having been told that there are some incommensurables, decisionmakers might possibly see them everywhere. ${ }^{32}$ Over a series of cases, therefore, some number of decisionmaking errors would be caused by taking the options as incommensurable when in fact they are commensurable. Moreover, when confronted with conflicting values, some decisionmakers might take the existence of incommensurable options, even options that are genuinely incommensurable, as a warrant for relying on their first, nonreflective impressions, rather than struggling with the difficult problems that come from trying rationally to come to a conclusion or make a decision. Although believers in the incommensurability of values maintain that choices can be made

${ }^{31}$ To be more precise, the inquiry turns on empirical psychological facts that are, even if not here, capable of being determined to some level of confidence by experimental or other empirical methods. In the absence of any good empirical evidence directed to anything even close to the question at issue, I will rely here on my own speculations.

${ }^{32}$ There is some experimental evidence indicating that people systematically overestimate the frequency or probability of low-probability events. See Daniel Kahneman \& Amos Tversky, Prospect Theory: An Analysis of Decision Under Risk, 47 ECONOMETRICA 263, 281 (1979) (stating that people would prefer paying an insurance premium "over a small probability of a large loss"); Sarah Lichtenstein et al., Judged Frequency of Lethal Events, $4 \mathrm{~J}$. EXPERIMENTAL PSYCHOL. 551, 556-57 tbl.2 (1978) (detailing the results of paired-comparison judgments for causes of death); David Laibson \& Richard Zeckhauser, Amos Tversky and the Ascent of Behavioral Economics 13-15 (Dec. 11, 1997) (unpublished manuscript, on file with the University of Pennsylvania Law Review) (concluding that decisionmakers make risk-seeking choices because they overweight low-probability events and underweight high-probability events). Sometimes this overestimation takes place with respect to low-probability opportunities, of which winning the lottery is certainly the most obvious example. Sometimes it takes place with respect to low-probability dangers, such as being bitten by a poisonous snake or being killed in an airplane crash. The fact that this phenomenon has been found to exist with respect to both opportunities and dangers lends support to the notion that people, if told that there are some, but not many, incommensurables or incomparables, will overestimate the frequency of incommensurables or incomparables in the aggregate, and with respect to particular cases, will have more false positives than false negatives. 
rationally when incommensurable values or reasons conflict, ${ }^{33}$ it is an empirical and not a normative question whether people, when confronted with what they believe to be such a conflict, will make the decision rationally, or even carefully. Even if there are incommensurables, therefore, it might be best to assume that there are not, at least if we indulge the assumption that overestimating the number of incommensurables might lead people to underestimate the number of times in which it would be fruitful to engage in difficult moral work.

It might be the case, however, that just the opposite is true. Suppose decisionmakers believe that there are no incommensurables, and that all values or reasons can be reduced to a common currency and thus balanced, weighed, or traded off against each other. Under such circumstances, it is possible that decisionmakers would be inclined to underestimate either certain values or the strength of certain reasons, perhaps as a consequence of looking for relative ease of calculation, or perhaps as a consequence of some tendency to equilibrate once we assume that equilibration is possible. Thus, it is possible that a belief in universal commensurability would lead people, in some cases, to assign mistakenly low values to certain reasons or certain options, and to do so more often than they would assign mistakenly high values. Moreover, a belief in universal comparability might slight certain values because of a certain psychological tendency to want both "sides" to win at about the same rate-a tendency we might think of as mistakenly centralizing for the sake of centralizing. ${ }^{34}$ Conversely, under different empirical conditions, we might think that it would be instrumentally valuable for people to believe that there were incommensurable values or reasons, even if there were not. ${ }^{35}$

ss See Gillian K Hadfield, An Expressive Theory of Contract: From Feminist Dilemmas to a Reconceptualization of Rational Choice in Contract Law, 146 U. PA. L. REV. 1235, 1259 (1998) ("Incommensurability, however, does not imply the impossibility of choice, of comparison between alternatives and selection among them.").

${ }^{34}$ Consider the norms of journalism, one of which is a requirement of "balance." If a prominent scientist gives a lecture asserting that there are no unidentified flying objects (UFOs), the norms of journalism are such that a story is likely to appear in which quotations from experts denying the existence of UFOs are balanced one-forone with quotes asserting the existence of UFOs. This one-for-one balance will determine the structure of the story even if there are almost certainly no UFOs, and thus will impart a quite imbalanced fact of the matter. If a similar norm exists for some cohort of decisionmakers, a consequence might be a centralizing tendency that would undervalue, or otherwise slight, very high, but properly very high, values.

${ }^{35}$ I believe that much the same can be said about the existence, or nonexistence, of moral dilemmas, an issue that plainly involves a closely related inquiry. See WALTER SINNOTT-ARMSTRONG, MORAL DILEMMAS (1988); BERNARD WILlIAMS, Conflicts of Values, in MORAL LUCK 71 (1981) (discussing the conflict between moral obligations and 
A different way of expressing the same basic point is to say that we can imagine decisionmakers possessing a disposition to commensurability, or, in contrast, a disposition to incommensurability. ${ }^{36}$ If decisionmakers possess a disposition to commensurability, they will approach any decision with the presumption that the alternatives could be reduced to a common metric and then weighed against each other. In many cases, this would of course be difficult. It would involve determining what the common metric is to be. It would involve attempting to make sure that the value is appropriately assigned. It would involve ensuring that all perverse, indirect, and secondary effects are fully taken into account. And, most of all, it would involve a tolerance for assigning values that reflect guesses, estimates, or points within ranges. But it would also engage decisionmakers in a process guided by the supposition that there is always, in theory, a right answer.

public order); BERNARD WILLIAMS, Ethical Consistency, in PROBLEMS OF THE SELF 166, 166 (1973) (discussing the "nature of moral conflict"); Earl Conee, Against Moral Dilemmas, 91 PHIL. REV. 87, 87 (1982) (stating that the possibility of moral dilemmas "would cast a shroud of impenetrable obscurity over the concept of moral obligation"); Ruth Barcan Marcus, Moral Dilemmas and Consistency, 77 J. PHIL. 121, 133 (1980) ("[T]he consistency of a set of moral rules ... is not incompatible with the reality of moral dilemmas."). Several years ago I attended a lecture by Isaac Levi, and I understood him to argue that it might be wise for people to believe that there were no moral dilemmas, even if there were, because a belief in the nonexistence of moral dilemmas would prevent people from departing prematurely from their own most difficult moral deliberations. This idea is what inspired some of the arguments I make here. In subsequent discussion, Levi has disclaimed making what I still believe to be an important point, so I will appropriate it myself since Levi apparently is willing to relinquish it.

${ }^{36}$ Although I do not address them directly here, various other decisionmaking approaches might also be thought of in terms of dispositions, attitudes, or presumptions. Thus, "satisficing, maximalizing, and absolutizing," Ruth Chang, Comparison and the Justification of Choice, 146 U. PA. L. REV. 1569, 1580 (1998) (emphasis omitted), for example, can be seen not only as ideal goals of decisionmaking, but as heuristics aimed at producing the optimal array of decisions by nonideal decisionmakers operating in a nonideal world.

${ }^{37}$ As the phrase in the text suggests, it is possible that much of what I argue here would be applicable to understanding Ronald Dworkin's claims about "right answers" in law. See generally RONALD DWORKIN, LAW'S EMPIRE (1986); RONALD DWORKIN, TAKING RIGHTS SERIOUSLY (1977); Ronald Dworkin, No Right Answer?, in LAW, MORALITY, AND SOCIETY, supra note 20, at 58, 59 (arguing that "the occasions in which a legal question has no right answer... must be much rarer than is generally supposed"). Even if there were not, in theory, a right answer to all (or perhaps even most) legal questions, we might still get better judging if all judges believed that there were. Indeed, if one understands Dworkin to be making claims about the phenomenology of judging more than about the ontology of law, Dworkin's claims about one right answer might be understood as descriptive claims about the dispositions, pre- 
Now if universal ${ }^{38}$ commensurability is false, then in at least some of the instances in which a commensurability-inclined decisionmaker approaches a decision, she will be inclined to impose a commensurability framework upon incommensurables. Perhaps one cost of this will be the cost of undervaluing one of the alternatives, or in some other way slighting the considerations that the recognition of the (stipulated) incommensurability will bring. This cost, however, may be weighed ${ }^{39}$ against the benefit of encouraging people to pursue the complete process of commensurating in those cases in which commensurability is true, as well as against the benefit of encouraging people to struggle with the decision as much as possible even in those cases in which commensurability is false.

If incommensurability is true, therefore, the question is whether adopting a universal presumption of commensurability will bring benefits in decisionmaking care sufficient to compensate for the undeniable costs of imposing an erroneous decision procedure with respect to those cases in which the values or reasons are in fact incommensurable. ${ }^{40}$ And making this determination will involve de-

sumptions, attitudes, and conceptual frameworks of American judges. A separate question then would be whether we get better judging from an array of judges with "one right answer" dispositions than we would get from an array of judges with "discretion" or "policy" dispositions. This would be an important question to ask, regardless of which of these dispositions most accurately reflected the underlying ontology or nature of law itself.

ss The claim of incommensurability denies that all values or reasons are commensurable, but, of course, does not claim that none are commensurable. Even someone who believes that the choice between losing a finger and getting a million dollars is a prime example of a choice between incommensurables would not deny that the choice between getting one million dollars and getting two million dollars (or, for that matter, between losing one finger and losing two fingers) is a choice between commensurables.

${ }^{39}$ This suggests the intriguing question of whether the costs and benefits of believing in commensurability or incommensurability are commensurable or incommensurable.

${ }^{10}$ Although I have been talking about decisionmaking, much of this discussion is also relevant to the question of how to deal with the consequences of a decision. (This is also a decisionmaking question, albeit of a different variety.) Suppose I believe that the choice between keeping a lunch date with you and leaving suddenly to attend to a sick relative is a choice between incommensurables, but that attending to the sick relative is plainly the right thing to do. And then suppose $I$ believe that this is a choice between commensurables and, again, that attending to the sick relative is the right thing to do. Now consider whether the believer in commensurability or the believer in incommensurability is more likely to try later to engage in some form of recompense (not necessarily in money, and preferably not in money), which I assume is the right thing to do. My hunch is that the believer in commensurability is more likely to perceive the moral residue from even the right decision, but this is psycho- 
termining what the costs and benefits would be of rejecting a presumption of commensurability (or, in a stronger version, adopting a presumption of incommensurability) if incommensurability is true. Such an inquiry into the costs of an ideal decision procedure in the hands of ideal decisionmakers obviously assumes that we will be in a nonideal world. And in this nonideal world, one possible cost is that people who presume the truth of incommensurability may, even if the presumption is accurate, nevertheless take that presumption as both warranting a less thoughtful approach to hard decisions than ought to be the case and suggesting that there are more incommensurables than is in fact the case. Put more bluntly, the possible risk is that a belief in incommensurability might, in the hands (or heads) of the wrong people, produce a less thoughtful approach to decisionmaking than would be produced, for those same people, by a belief in universal commensurability and, most importantly for my claims here, that this might be so, in the aggregate, even if the belief in incommensurability is sound.

As I have suggested, the same analysis can be run in the opposite direction, subject to one important asymmetry. The asymmetry is that a belief in the position commonly known as incommensurability does not commit the believer to the position that all conflicts of values, reasons, or options involve conflicts of incommensurable values or norms, but only to the position that there is at least one conflict between incommensurable values or norms. In contrast, however, a belief in the position commonly known as commensurability commits the believer to the position that all reasons or values are commensurable. Consequently, the existence of one incommensurable pair renders commensurability false, but the existence of one commensurable pair does not even come close to rendering incommensurability false.

Still, it can be useful to see how the analysis looks if there exists a widespread disposition to incommensurability even if commensurability better reflects the actual state of the relevant universe. One scenario under which such a state of affairs might be desirable is the scenario-quite possibly reflecting much of the concern (for people who have a concern) about cost-benefit analysis that some people have been expressing since the early 1980s-in which a cost-benefit analysis places mistakenly low values on human life, the environment,

logical speculation, and I can imagine someone reaching exactly the opposite conclusion. What I find harder to imagine, however, is that this is not a question that ought to be asked in thinking about the larger questions of commensurability. 
the preservation of endangered species, future generations, ${ }^{41}$ and so on. Since we are presuming the truth of commensurability as an ontological position, the values of life, the environment, and the preservation of endangered species are, inter alia, subject to being assigned a value on the same metric as the value of having trains run on time, the value of having a house of a certain size, the value of having a job paying such-and-such a wage, the value of being able to go to the movies once a week, and the value of a painting by Van Gogh. But even though commensurating all of these things is, under our assumption, theoretically possible, and even though, again under our assumption, there is a right answer to the question of what each is worth in terms of the commensurating "currency," it is quite possible that ordinary decisionmakers systematically will underestimate some of the values, including perhaps the values of life and the environment. ${ }^{42}$ Under such circumstances, it might be better-that is, produce better decisions on the assumption that all values are commensurable-if decisionmakers believed that the values of life and the environment were incommensurable. This claim could of course be tested, and indeed should be tested, but it hardly seems implausible to suppose that people would place a higher imputed value on human life when told that human life was incommensurable with anything else than they would when told that human life could be valued in the same currency as more efficient railway transportation.

The foregoing discussion was premised upon the assumption that the institutional designers ${ }^{43}$ knew whether commensurability accu-

${ }^{11}$ It might also be the case that people apply an erroneous discount rate to future generations.

${ }^{42}$ It is highly likely that the tendency to so underestimate by the people who are actually implementing monetized cost-benefit analyses is one reason for much of the "skepticism about the moral status of [cost-benefit analysis]." Matthew Adler, Incommensurability and Cost-Benefit Analysis, 146 U. PA. L. REV. 1371, 1373 (1998). Adler takes the absence of a satisfactory defense in the literature (an empirical claim with which I agree) as causally related to the empirical fact of widespread skepticism. See id. at 1372-73. I am more dubious. If the numbers or dollars assigned to lives and the environment in existing cost-benefit analyses had been higher, and if the outcomes of such analyses had rejected a substantially higher number of life-risking or environment-risking projects, I suspect that there would have been much less skepticism.

${ }_{43}$ The standpoint of the institutional designer need not presuppose the kind of "us-them" or "archangel-prole" division that one finds in, for example, R.M. HARE, MORAL THINKING 44-64 (1981). All of us occupy different roles even vis-à-vis ourselves, and, in circumstances under which I am designing institutions or dispositions to constrain my future behavior, I exist in the role of institutional designer, even if I am designing an institution solely for myself. 
rately represented the fact of the matter. Another possibility, of course, as the papers in this Symposium indicate and the debates of the last two decades signify, is that we are unsure, as between commensurability and incommensurability, which is actually true. Under these circumstances, we could and should make the foregoing analysis even more complex by examining the costs of a widespread belief in commensurability if commensurability is false, examining the costs of a widespread belief in incommensurability if incommensurability is false, estimating the relevant probabilities, and putting all of these costs and probabilities through a full-scale decision-theoretic analysis just as we would decide anything else under conditions of uncertainty.

If we were to undertake this task, we would want to take into account not only the philosophical uncertainties about whether commensurability or incommensurability is the better position philosophically, but also the philosophical uncertainties about which decisions would be better and the empirical uncertainties about how people would behave under various different beliefs, dispositions, attitudes, and presumptions. This task is of course, in theory, a daunting one, and not much less daunting in practice, where we can substitute guesses for more extensive empirical investigations. My message here, however, is not about the ways in which we perform the task. Rather, it is about what we conceive the task to be. One task is the task of determining which, as between commensurability and incommensurability, or between comparability and incomparability, is the wiser, sounder, better justified, or more likely true position as a matter of philosophical first principles. Another task, however, is the task of determining, as between commensurability and incommensurability, or between comparability and incomparability, which is the belief, disposition, attitude, presumption, or whatever else that it would be better for some cohort of decisionmakers to have. ${ }^{44}$ As the immediately preceding paragraph suggests, it would be a mistake to think that the question of which belief it would be better for some group of decisionmakers to have can be answered without reference to the answer, as best we can determine it, to the question of which

${ }^{41}$ If it is determined that some cohort of decisionmakers would be better off operating in a framework of commensurability, one possible mechanism for bringing out this end is by excluding potentially incommensurable values or reasons from those decisionmakers' jurisdiction. See Richard Warner, Excluding Reasons: Impossible Comparisons and the Law, 15 OXFORD J. LEGAL STUD. 431, 433 (1995) (stating that legal determinations of irrelevance can serve to exclude reasons that should not, for moral reasons, be part of a decisional calculus). 
position is actually true. But, as most of this Article has tried to suggest, and as a rich literature from John Stuart Mill through numerous modern embellishments of consequentialism has urged, ${ }^{45}$ it also would be a mistake to suppose that the answer to the question of which position is true determines conclusively the answer to the question of which position it would be better to have. A wide range of decisionmaking devices and heuristics, of which rules are the most prominent, are premised on the "falsity," in some sense, of certain decisionmaking devices. Once we recognize that dispositions are like rules, and that dispositions might be chosen for instrumental reasons, we can no longer think that the relevant moral inquiry, in a secondbest world, will end even if we are successful in answering the important ontological questions about commensurability.

is See sources cited supra notes 24-25. 
$* \quad * \quad * \quad * \quad * \quad *$ 